University of New Hampshire

University of New Hampshire Scholars' Repository

$10-2002$

\title{
Near bottom sediment characterization offshore SW San Clemente Island
}

\author{
Daniel D. Sternlicht \\ University of California - San Diego \\ Christian de Moustier \\ University of California - San Diego
}

Follow this and additional works at: https://scholars.unh.edu/ccom

Part of the Oceanography and Atmospheric Sciences and Meteorology Commons

\section{Recommended Citation}

Sternlicht, Daniel D. and de Moustier, Christian, "Near bottom sediment characterization offshore SW San Clemente Island" (2002). IEEE Oceans. 257.

https://scholars.unh.edu/ccom/257

This Conference Proceeding is brought to you for free and open access by the Center for Coastal and Ocean Mapping at University of New Hampshire Scholars' Repository. It has been accepted for inclusion in Center for Coastal and Ocean Mapping by an authorized administrator of University of New Hampshire Scholars' Repository. For more information, please contact Scholarly.Communication@unh.edu. 


\title{
Near Bottom Sediment Characterization Offshore SW San Clemente Island
}

\author{
Daniel D. Sternlicht ${ }^{a}$ and Christian P. de Moustier $^{b}$ \\ ${ }^{a}$ ORINCON Defense, 4770 Eastgate Mall, San Diego, CA 92121 \\ dsternlicht@orincon.com \\ ${ }^{\mathrm{b}}$ Center for Coastal and Ocean Mapping, University of New Hampshire, Durham, NH 03824 \\ cpm@ccom.unh.edu
}

\begin{abstract}
Normal incidence, $23.5 \mathrm{kHz}$ seafloor acoustic backseatter data and bottom video were measured with the Deep Tow instrument package of the Scripps Institution of Oceanography in 100 meter water depth south of San Clemente Island, $\mathrm{CA}$. The collected data were processed using an echo envelope sediment characterization method, to derive geoacoustic parameters such as particle mean grain size and the strength of the power law characterizing the roughness energy density spectrum of the sediment-water interface. Two regions, sand and silt, were selected based on available ground truth, perceived along-track sediment homogeneity, data quality and tow fish stability. Distinction between sand and fine grain sediments can be accomplished by creation of feature vectors comprised of mean grain size $\left(M_{\phi}\right)$ and interface roughness spectral strength $\left(w_{2}\right)$. Estimates for mean grain size and roughness spectral strength $\left(M_{b}, w_{2}\right)$ were $(1.5$, $0.0095)$ for sand, and $(6.7,0.0033)$ for silt, where $M_{b}$ is expressed in PHI units, and $w_{2}$ has units $\mathrm{cm}^{4}$. These results are consistent with local ground truth measurements and i)lustrate the potential of this sediment characterization method in survey mode.'
\end{abstract}

\section{INTRODUCTION}

Acoustic classification of ocean sediments is motivated by a variety of commercial and military activities, which include communication cable and pipeline route planning, mineral resources assessment, acoustic propagation modeling for undersea surveillance, and sediment characterization for littoral mining and de-mining activities. This work describes the testing of an echo envelope sediment characterization method $[1,2]$ on vertical incidence fathometer data collected during a cable route planning survey.

Seafloor acoustic backscatter data and bottom video were measured with the Deep Tow instrument package of the Scripps Institution of Oceanography in 100-meter water depth south of San Clemente Island, CA. Echo envelope data from the $23.5 \mathrm{kHz}$ vertical incidence sonar were compared to a physical model to derive geoacoustic parameters including: mean grain size, strength and exponent of the power law characterizing the roughness energy density spectrum of the sediment-water interface, and the sediment volume acoustic absorption and scattering coefficients. Mean grain size leads to acoustic impedance of the sediment or its constituents: density and sound speed.

\footnotetext{
' This work was sponsored by the Office of Naval Research under contract \# N00014-97-D-0350.

$0-7803-7534-3 / \$ 10.00$ C2002 IEEE
}

The bottom echo intensity envelope model used in this work [1] is a temporal implementation of the SONAR equation [3], based on analytical tools developed by de Moustier and Alexandrou [4] for modeling seaffoor echoes measured with multibeam seafloor mapping sonars. Similar temporal models described by others include Berry $[5,6]$, Nesbitt [7], and Pouliquen and Lurton [8,9].

Section II of this paper introduces the sediment characterization method. Section III describes the acoustic sensor and system calibration. Section IV describes the hydrographic survey. Section V presents the optimization results and associated geoacoustic parameter estimates. Section VI summarizes the work and suggests avenues of further research.

\section{SEDIMENT CHARACTERIZATION METHOD}

The geoacoustic characteristics of the sediment-water interface and top layer of sediment are determined by comparing bottom returns measured with a calibrated, moderate beam width (10-20 degree) fathometer with an echo envelope model based on high frequency (10-100 $\mathrm{kHz}$ ) incoherent backscatter theory [10] and sediment properties such as mean grain size, strength and exponent of an interface roughness spectrum exhibiting power law statistics, and volume scattering coefficient.

The four function modules illustrated in Fig. 1 summarize the parameter estimation technique. An average intensity envelope is calculated from aligned echoes measured over a distance commensurate with the transducer's footprint. It is compared to an echo model that incorporates the system's deployment geometry, beam pattern, and signal characteristics; the ocean volume spreading and absorption losses; and the geoacoustic parameters that describe the sediment interface and volume scattering statistics. The model component representing interface scattering incorporates the relief spectrum and a coherent reflection coefficient. Scattering from the subbottom is derived from the sound absorption coefficient and refraction index fluctuations of the bottom medium, as well as the interface characteristics governing sound transmission to the sediment.

An average echo envelope matching procedure is employed (module 4 of Fig. 1) where: first, sediment type (sand or fines) is established by iterating on the reflection coefficient to match the peak echo amplitude and to 


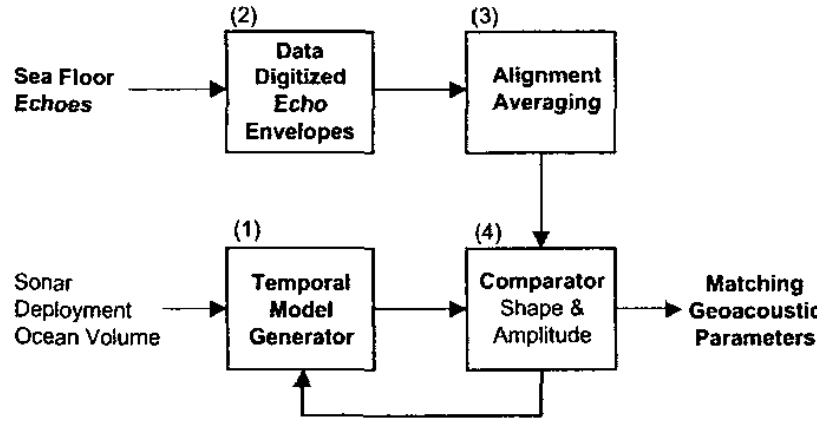

Fig. 1. Sediment geoacoustic parameter estimation method.

establish a general fit with generic values for the remaining geoacoustic parameters; then, a three parameter global optimization is performed using a combination of simulated annealing and downhill simplex searches over the allowable range of interface roughness spectral strength, sediment volume scattering coefficient, and a constrained range of reflection and bottom absorption coefficients correlated with mean grain size [1].

\section{SONAR SYSTEM}

The $23.5 \mathrm{kHz}$ sonar used in this work uses a Line-and-Cone transducer that is typically installed on the vehicle as an uplooking sonar. The acoustic frequency and beam width are well suited for sediment characterization; thus, the device was re-mounted in a down-looking orientation and interfaced to a $500 \mathrm{kHz}$ analog to digital (A/D) converter for echo envelope extraction. General information on Line-and-Cone transducers and on the Deep Tow sensor suite can be found in [11,12].

The relevant operating characteristics of the $23.5 \mathrm{kHz}$ Deep Tow Line-and-Cone sonar system are: $3-\mathrm{dB}$ and 6-dB beam widths $\left(\theta_{3 \mathrm{~dB}}=16^{\circ}\right.$ and $\left.\theta_{6 \mathrm{~dB}}=21^{\circ}\right)$, transmit pulse length $\left(\tau_{\mathrm{p}}=1 \mathrm{msec}\right)$, transmit voltage response (TVR $161.2 \mathrm{~dB}$ re: $1 \mu \mathrm{Pa} / \mathrm{Volt} @ 1 \mathrm{~m}$ ), open circuit voltage response ( $\mathrm{OCV}-186 \mathrm{~dB}$ re: $1 \mathrm{Volt} \mu \mathrm{Pa}$ ), ping repetition rate $1 \mathrm{~Hz}$ and receiver gain $26 \mathrm{~dB}$.

Transmit and receive beam patterns for the Line-andCone transducer were measured at $f_{a}=25 \mathrm{kHz}$, i.e., $1.5 \mathrm{kHz}$ above the operational value. To obtain a radiation pattern for the survey acoustic frequency $(23.5 \mathrm{kHz})$, the theoretical beam pattern of a piston transducer at $25 \mathrm{kHz}$ was matched to the measurements. The beam pattern model was then gencrated for $f_{a}=23.5 \mathrm{kHz}$ and used in the echo envelope model software which, at this stage of development, utilizes theoretical radiation patterns.

A comparison of measured and theoretical beam patterns for the Line-and-Cone transducer is shown in Fig. 2. The circles and stars represent measured transmit and receive patterns respectively for $f_{a}=25 \mathrm{kHz}$, and the solid line represents the computed average. The dashed line represents the $(0-6 \mathrm{~dB})$ best-fit theoretical radiation pattem for a generic piston transducer operating at $f_{a}=25 \mathrm{kHz}$, which has an aperture radius of $12 \mathrm{~cm}$ [13].

Figure 3 shows the generic $23.5 \mathrm{kHz}$ radiation pattern. In this analysis, the echo envelope model computes and uses generic piston transducer radiation values using parameters $\left(f_{a}=23.5 \mathrm{kHz}\right.$, radius $\left.=12 \mathrm{~cm}\right)$. A minor deficiency is that the moderate 6-dB side lobes inherent to the Line-and-Cone transmit response are not accounted for.

For comparison of model and data, the echo envelope model utilizes a digitized representation of the transmitted signal, and measured voltage waveforms are converted to their respective pressure waveforms using the receiver characteristics.

Independent measures of the transmitted signal and the transducer's mechanical-electrical transfer function [1] were not available for this survey system; thus, a generic 1-msec transmit signal shape was employed and an OCV scaled gate transfer function was assumed. The transmit signal envelope employed in this study is an interpolated version of the transmit signal for a Reson TC2084 $33 \mathrm{kHz}$ piston transducer, employed in [1]. The estimated transmit signal envelope is depicted in Fig. 4, where the sample frequency is set equal to $23.5 \mathrm{kHz}$, the same as the acoustic transmit frequency. The nonconformity with the actual signal's rising and falling edge characteristics naturally introduces some distortion into the geoacoustic inversions.

\section{HYDROGRAPHIC SURVEY}

The backscatter data analyzed consist of Deep Tow survey measurements conducted along the track shown in Fig. 5. Survey locations are inferred from the ship's navigation records, adjusted for vessel speed and length of the short tether.
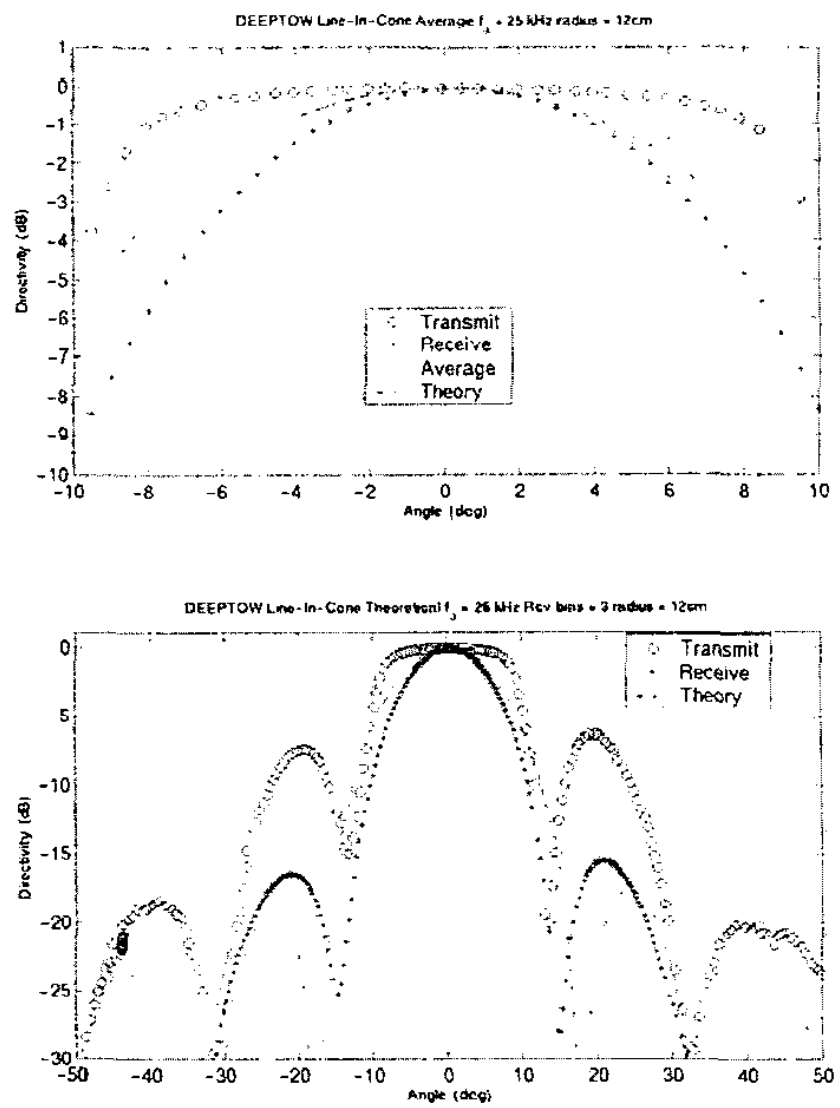

Fig. 2. Theoretical vs. measured beam patterns for Line-and-Cone transducer. 


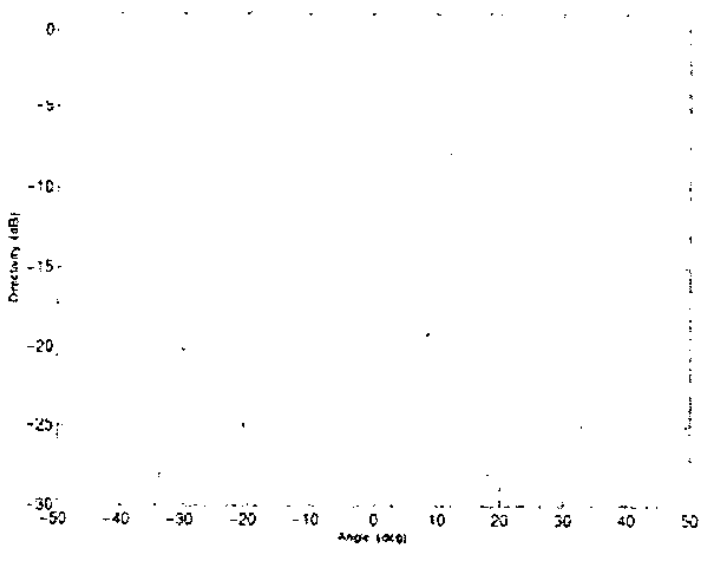

Fig. 3. Theoretical beam pattern for generic piston transduzer $(\mathrm{fa}=23.5 \mathrm{kHz}$, radius $=12 \mathrm{~cm})$.

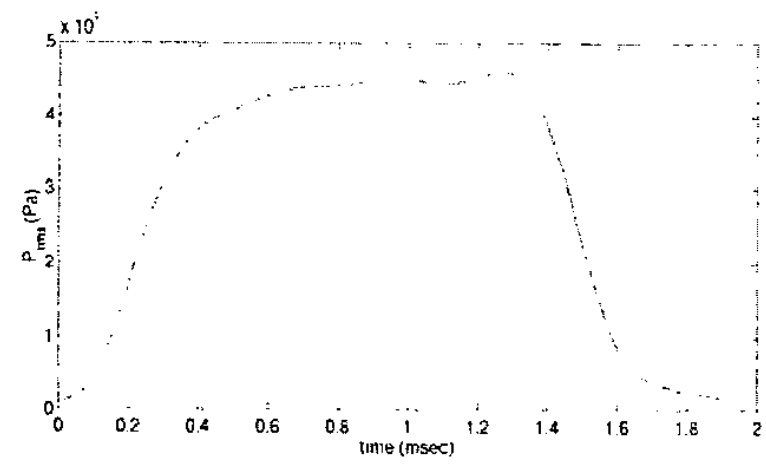

Fig. 4. Estimated transmit signal envelope.

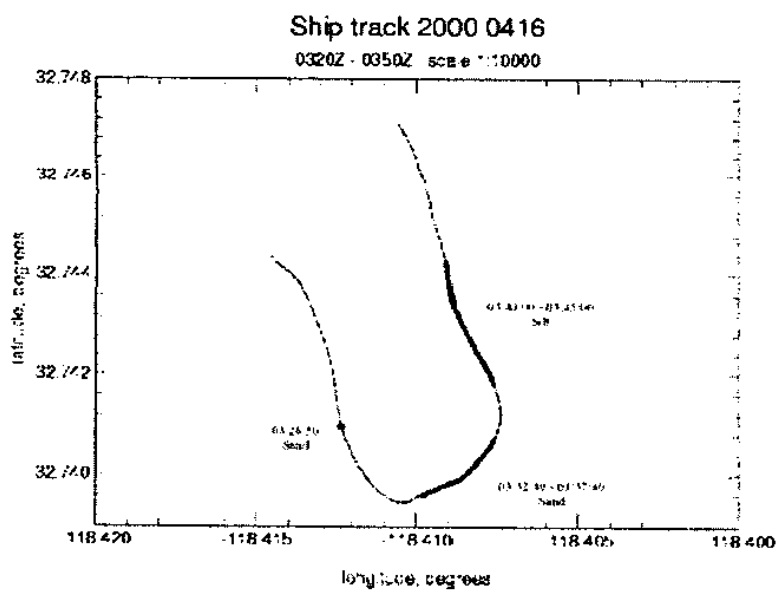

Fig. 5. Survey track chart.

The sand site consists of an isolated 100-meter N-S stretch and a 300-meter SW-NE trackline, whereas the silt site consists of a 300-meter S-N trackline. Grain size analyses of grab samples collected during the survey indicate that granular sediment types distributed throughout the area range from coarse sand to fine silt. Seafloor video images taken adjacent to the sand site (Fig. 6) indicate the presence of a sandy substrate.

Site boundaries were selected based on data quality, where the main criteria are acoustic signal-to-noise ratio, perceived along-track sediment homogeneity, and tow fish stability. Consistency in echo character (i.e., shape and arnplitude measured along-track) serves as a reasonable indication of spatial seafloor homogeneity. Such an example is shown in the waterfall and raster plots of Fig. 7, where low-amplitude pings 2500-2800, representing retums from the silt survey region, exhibit the consistency necessary for our stochastic approach to acoustic sediment characterization.

Fig. 8 shows the transducer's elevation angle above vertical incidence $\left(\theta_{\mathrm{T}}\right)$ for the ping series 2500 to 2600 , as measured by the Deep Tow system attitude sensor. The standard deviation of $\theta_{\mathrm{T}}$ over 100 pings is typically 1 degree or less, which is acceptable for this analysis.

Survey parameters consist of transducer elevation angle, making allowances for bottom slope; sensor altitude above the seafloor; along-track $3 \mathrm{~dB}$ and $6 \mathrm{~dB}$ footprint diameters (i.e., the diameter of the transducer's radiation print along the seafloor); transmission source level; and model-data optimization parameters that will be discussed in section $\mathrm{V}$.

\section{SEDIMENT CHARACTERIZATION RESULTS}

The measured bottom echo consists of a pulsed CW signal modulated by the echo envelope. Envelope detection of this signal, a $500 \mathrm{kHz}$ to $23.5 \mathrm{kHz}$ band shift and filter operation, yields an $\mathrm{mms}$ pressure time series, $p[n]$, expressed in units of Pascals (Pa). As illustrated in Fig. 7, the bottom echoes measured are largely incoherent, varying in amplitude and shape as the sonar translates longitudinally above the interface. Because of this variability, echoes are treated stochastically, where $M$ pings are aligned and averaged.

In [14], a number of alignment and averaging techniques were evaluated for generating appropriate average echo envelopes from data. It was found that echo alignment along threshold minima indexes best preserves leading-edge echo characteristics, a useful feature in the geoacoustic inversion. For echoes with a well defined initial rise and peak amplitude followed by a gradual decay, threshold minima alignment is possible; however, for pings with poorly defined temporal features (found in the data presented here) alignment indexes are calculated using the phase slope (group delay) of envelope spectra. The resulting alignment index is based on energy contributions spanning the entire length of the retum, rather than on a single temporal feature; thus, producing average echoes more consistent with theory.

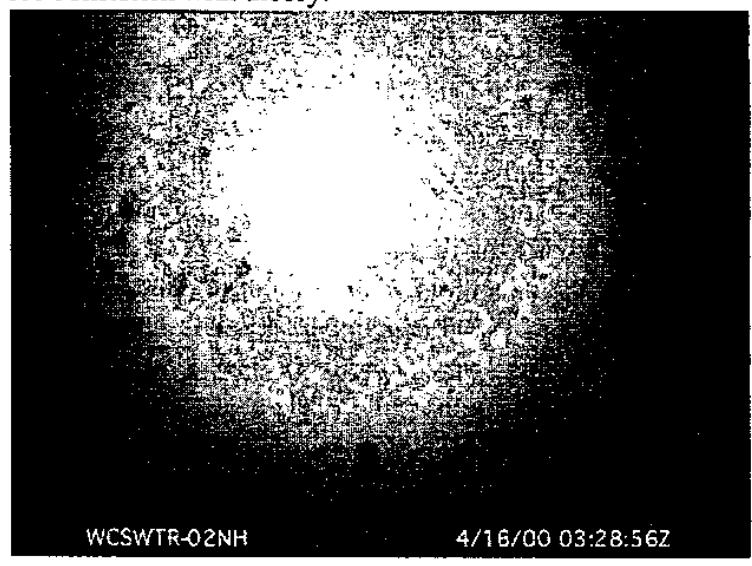

Fig. 6. Bottom photograph: Sand substrate with assorted starfish. 

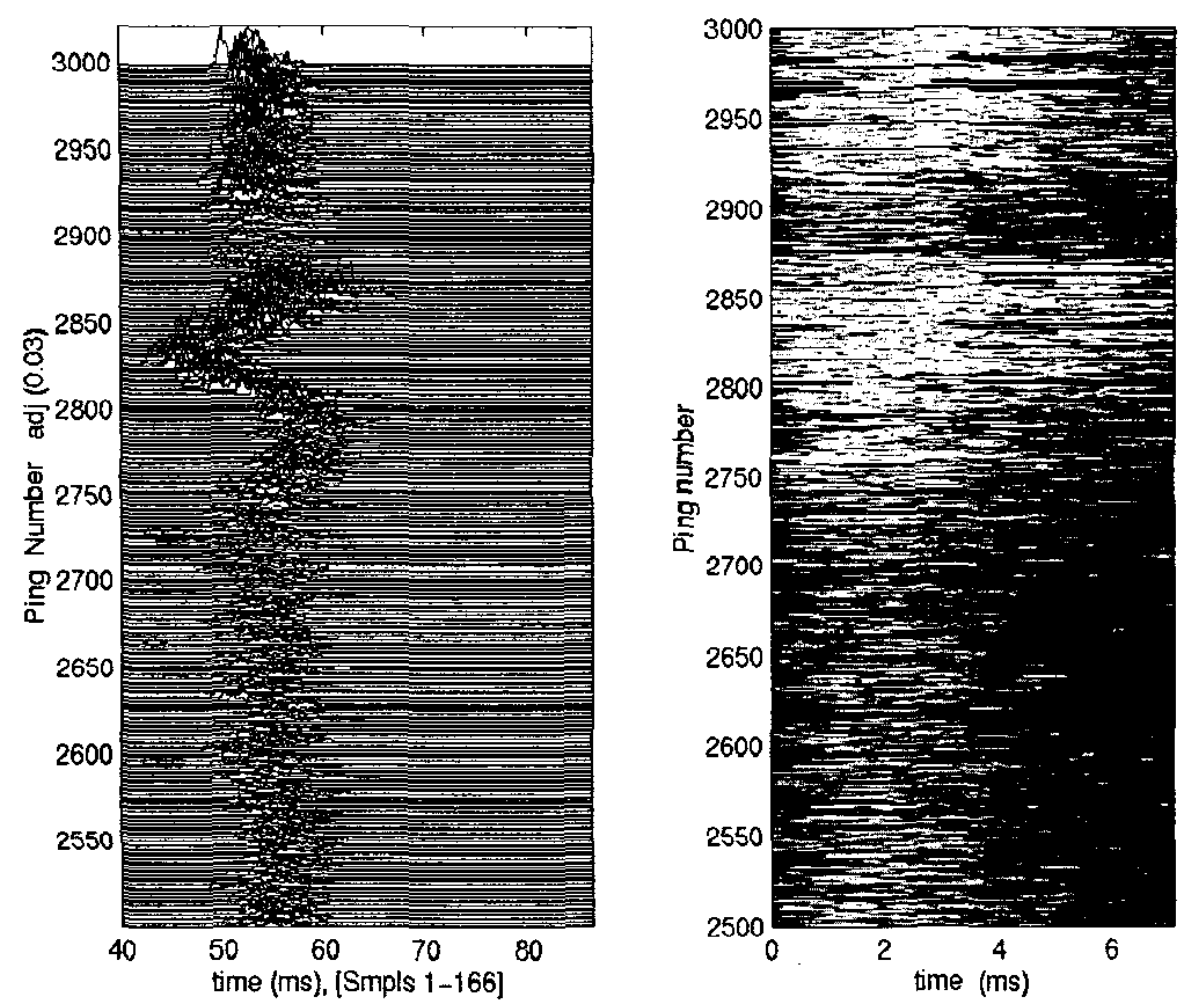

Fig. 7. Echo envelope waterfall and raster plots representing RMS pressure time series of 1000 consecutive pings collected at $1 \mathrm{~Hz}$.

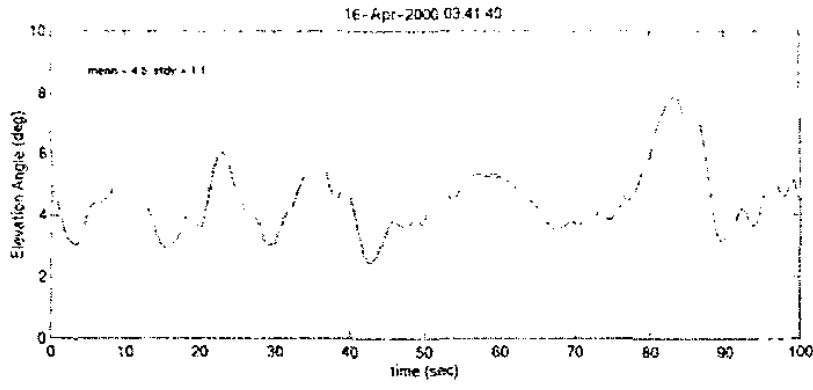

Fig. 8. Measured transducer elevation angle above vertical incidence.

In [14], it was also determined that the appropriate number of pings to be averaged should equal or exceed the number that it takes to traverse the transducer's $6-\mathrm{dB}$ foot print. The 6-dB footprint diameters for this survey are on the order of 20 meters. For the tow speed of 2 knots (1 meter/second) and ping repetition rate of $1 \mathrm{~Hz}$, this criterion is satisfied by using 20 pings. However, experimentation with the data presented here revealed that ping ensembles on the order of $M=100$ are necessary to create average echo envelopes having adequate smoothness for model-data optimization.

\section{A. Geoacoustic Inversions}

The two-stage model-data optimization technique summarized in Section II and described in [1] was applied to average echo envelopes from the sand and sitt sites. For each site the estimated geoacoustic parameters describing the watersediment interface and sediment volume are summarized as:
$\mathrm{M}_{\phi}=$ mean grain size in $\mathrm{PHI}$ units

$\gamma=$ water-sediment interface roughness spectral exponent

$w_{2}=$ water-sediment interface roughness spectral strength in $\mathrm{cm}^{4}$

$\sigma_{\mathrm{v}}=$ sediment volume scattering coefficient in $\mathrm{m}^{-1}$

$b=$ empirical macro roughness parameter (in number of standard deviations)

Estimates for these parameters, along with the modeldata signal to error ratios (S/E), are listed in Tables I and II, with S/E representing the "goodness" of the fit:

$$
S / E=\frac{\sum_{n=n_{1}}^{n_{2}} p_{a}^{2}[n]}{\sum_{n=n_{1}}^{n_{2}}\left(p_{a}[n]-\hat{p}_{a}[n]\right)^{2}}
$$

where $p_{a}$ is the averaged data waveform, $\vec{p}_{a}$ represents the model waveform, and $n_{1}$ and $n_{2}$ are the initial and final indexes for each waveform. Approximately five modeldata matches are listed for each scenario, the overlap between data segments being $50 \%$ or less. In accordance with the model-data matching paradigm outlined in [1], a volume scattering penalty is applied to the sand model-data goodness calculations to discourage unrealistic solutions of sediment volume backscatter energy exceeding that of the water-sediment interface.

Fig. 9 illustrates the model-data comparison of average echo index number 1 for each of the sand and silt substrates. The relative interface and sediment volume 
contribution to the computed sound pressure field are plotted on the same graph, illustrating the dominance of the interface component in the early portion of the signal and that of the volume component in the latter portion of the signal.

First-and second-order statistics of the compiled results are listed in Table III. A summary of model-data matches is presented in Table IV, in which the mean values are rounded off to the nearest one-tenth value. Here, geoacoustic parameters:

$\rho=$ sediment $/$ water density ratio

$v=$ sediment/water sound speed ratio

$\kappa_{\mathrm{p}}=$ sediment compressional wave attenuation constant $(\mathrm{dB} / \mathrm{m} / \mathrm{kHz})$

are calculated from $M_{\phi}$ with relationships described in $[1,15]$.

\section{B. Estimates of Mean Grain Size $\left(M_{\phi}\right)$}

Given a priori knowledge of local ground truth (sediment samples and bottom video), the estimates of mean grain size, centering about $M_{\phi}=1.5$ for sand and $M_{\phi}=6.7$ for silt, are realistic. This is due largely to effective matching of model and data peak amplitudes. The signal amplitude is largely a function of the acoustic impedance contrast $(\rho v)$ influence on the reflection coefficient $R\left(\theta_{i}\right)$

$$
R\left(\theta_{i}\right)=\frac{\rho \nu \cos \left(\theta_{i}\right)-\left[1-\left(\nu \sin \left(\theta_{i}\right)\right)^{2}\right]^{1 / 2}}{\rho \nu \cos \left(\theta_{i}\right)+\left[1-\left(\nu \sin \left(\theta_{i}\right)\right)^{2}\right]^{1 / 2}}
$$

where $\theta_{i}$ is the angle the incident sound wave makes with the seafloor. These results are obtainable due to sensor calibration procedures carried out on the Line-and-Cone transducer subsystem, and are reliable to the extent that the equations relating $\rho v$ to $M_{\phi}$ accurately reflect the substrates under study.

TABLE 1

TWO-STAGE AVERAGE ECHO PARAMETER ESTIMATION Sand, $23.5 \mathrm{kHz}, \theta_{\mathrm{T}}=3^{\circ}, b=0.5, \gamma=3.0$

\begin{tabular}{|c|c|c|c|c|}
\hline Average & $\begin{array}{c}\text { Mean } \\
\text { Echo Index } \\
\text { Size } \\
\text { Mø }\end{array}$ & $\begin{array}{c}\text { Spectral } \\
\text { Strength } \\
w_{2}\left(\mathrm{~cm}^{4}\right)\end{array}$ & $\begin{array}{c}\text { Volume } \\
\text { Scatter } \\
\text { Coeff } \\
\sigma_{v}\left(\mathrm{~m}^{-1}\right)\end{array}$ & $\begin{array}{c}\text { Model- } \\
\text { Dlata Fit } \\
\text { S/E (dB) }\end{array}$ \\
\hline 1 & 1.24 & 0.00967 & 0.571 & 8 \\
\hline 2 & 0.35 & 0.00839 & 0.040 & 13 \\
\hline 3 & 0.97 & 0.00998 & 0.505 & 10 \\
\hline 4 & 1.98 & 0.00958 & 0.472 & 11 \\
\hline 5 & 2.20 & 0.00962 & 0.441 & 12 \\
\hline 6 & 2.23 & 0.00976 & 0.441 & 11 \\
\hline
\end{tabular}

TABLE II

Two-Stage Average Echo Parameter Estimation Silt, $23.5 \mathrm{kHz} . \theta_{\mathrm{T}}=5^{\circ}, b=1.28, \gamma=3.3$

\begin{tabular}{|c|c|c|c|c|}
\hline $\begin{array}{c}\text { Average } \\
\text { Echo Index }\end{array}$ & $\begin{array}{c}\text { Mean } \\
\text { Size } \\
\text { Mø }\end{array}$ & $\begin{array}{l}\text { Spectral } \\
\text { Strength } \\
w_{2}\left(\mathrm{~cm}^{4}\right)\end{array}$ & $\begin{array}{c}\text { Volume } \\
\text { Scatter } \\
\text { Coeff } \\
\sigma_{v}\left(\mathrm{~m}^{-1}\right)\end{array}$ & $\begin{array}{c}\text { Model- } \\
\text { Data Fit } \\
\text { S/E (dB) }\end{array}$ \\
\hline 1 & 6.60 & 0.00489 & 0.033 & 25 \\
\hline 2 & 7.15 & 0.00494 & 0.019 & 25 \\
\hline 3 & 7.53 & 0.00473 & 0.013 & 21 \\
\hline 4 & 7.06 & 0.00164 & 0.013 & 19 \\
\hline 5 & 5.09 & 0.00025 & 0.155 & 15 \\
\hline
\end{tabular}

\section{Relief Spectrum Strength $\left(\mathrm{w}_{2}\right)$ vs. Mean Grain Size $\left(M_{\phi}\right)$}

The $w_{2}$ estimates for sand (mean value of 0.0095 ) are typically several times greater than those for silt (mean value of 0.0033 ). However, these values are several times larger than those for similar substrates surveyed in San Diego Bay [1]. A physical explanation of this phenomenon is that these substrates exhibit more power in the relief spectra (i.e. are "rougher") than the San Diego Bay substrates. Another possible reason for this result is that the optimization method, in its search for the best model-data match, over-compensated for $w_{2}$. The reason for this will be discussed in section V.E.

\section{Estimates of Sediment Volume Scattering $\left(\sigma_{v}\right)$}

Estimates of the volume scattering coefficient $\left(\sigma_{v}\right)$ are perhaps the most difficult to interpret and, as in the San Diego Bay study [1], standard deviations greater than $3 \mathrm{~dB}$ from the mean value are not uncommon. This variation may be due to real changes in the statistics governing neighboring patches of seafloor. Indeed, the mean values shown here $(0.43$ for sand and 0.05 for silt) roughly match the corresponding values derived in the San Diego Bay survey: 0.20 for sand substrate, $f_{a}=33 \mathrm{kHz}$, vertical incidence; 0.07 for silt substrate, $f_{a}=33 \mathrm{kHz}$, vertical incidence. However, as with the $w_{2}$ estimates, these results may be due to over-compensation in the model-data matching procedure.

\section{E. Discussion}

The echo measurements in this experiment were collected under operating conditions that were not as well controlled as those in the former San Diego Bay study [1]. The objective of the San Diego Bay study was to develop an acoustic sediment characterization approach, whereas the data analyzed here were an experimental adjunct to a comprehensive multi-sensor oceanographic survey. While essential components for preprocessing the data and performing the model-data 


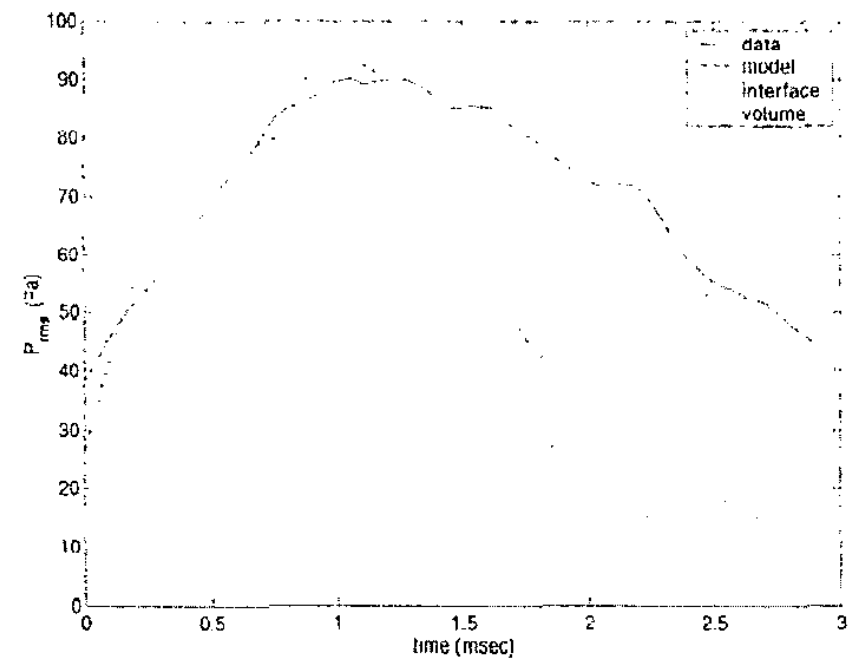

(a)

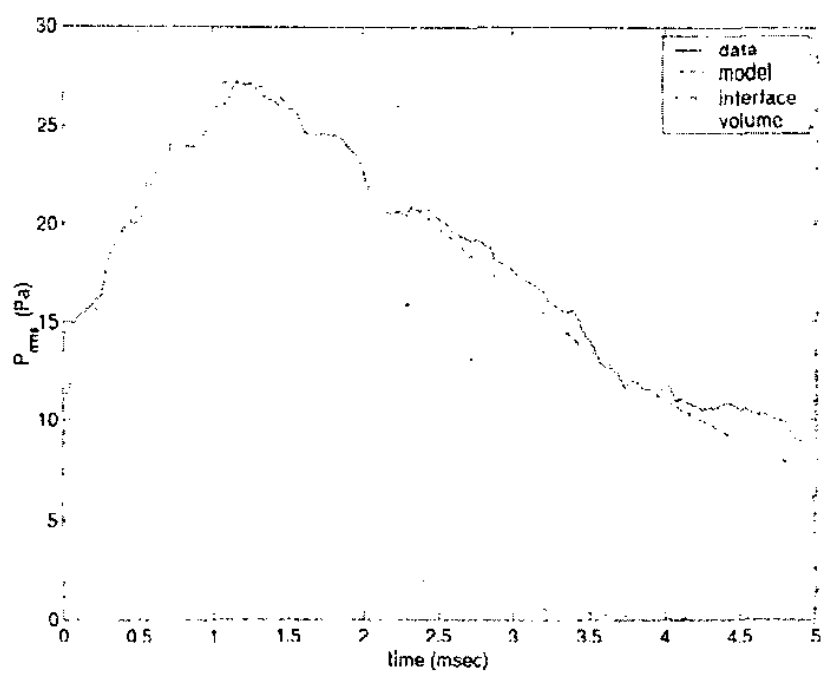

(b)

Fig. 9. Model-data echo envelope comparisons.

(a) Sand Substrate: Model parameters: $\mathrm{M}_{\phi}=1.24, \gamma=3.0, w_{2}=0.00967 \mathrm{~cm}^{4}, \sigma_{\mathrm{v}}=0.571 \mathrm{~m}^{-1}, \theta_{\mathrm{T}}=3^{\circ}, b=0.5 . \mathrm{S} / \mathrm{E}=8 \mathrm{~dB}$.

(b) Silt Substrate: Model parameters: $\mathrm{M}_{\phi}=6.60, \gamma=3.3, w_{2}=0.00489 \mathrm{~cm}^{4}, \sigma_{\mathrm{v}}=0.033 \mathrm{~m}^{-1}, \theta_{\mathrm{T}}=5^{\circ}, b=1.28 . \mathrm{S} / \mathrm{E}=25 \mathrm{~dB}$.

TABLE III

SEDIMENT ChaRACTERIZATION StaTISTICS

\begin{tabular}{|l|c|c|c|c|c|c|c|}
\hline \multicolumn{1}{|c|}{ Site } & $\begin{array}{c}\text { Mean } \\
\text { Mø }\end{array}$ & $\begin{array}{c}\text { Stdv } \\
\text { Mø }\end{array}$ & $\gamma$ & $\begin{array}{c}\text { Mean } \\
w_{2}\left(\mathrm{~cm}^{4}\right)\end{array}$ & $\begin{array}{c}\text { Stdv } \\
w_{2}\left(\mathrm{~cm}^{4}\right)\end{array}$ & $\begin{array}{c}\text { Mean } \\
\sigma_{v}\left(\mathrm{~m}^{-1}\right)\end{array}$ & $\begin{array}{c}\text { Stdv } \\
\sigma_{v}\left(\mathrm{~m}^{-1}\right)\end{array}$ \\
\hline Sand & 1.49 & 0.76 & 3.00 & 0.00950 & 0.00056 & 0.433 & 0.199 \\
\hline Silt & 6.69 & 0.95 & 3.30 & 0.00329 & 0.00220 & 0.046 & 0.061 \\
\hline
\end{tabular}

TABLE IV

SEDIMENT CHARACTERIZATION SUMMARY

\begin{tabular}{|l|c|c|c|c|c|c|c|}
\hline \multicolumn{1}{|c|}{ Site } & $\begin{array}{c}\text { Mean } \\
\text { Grain } \\
\text { Size } \\
\mathrm{Mø}\end{array}$ & $\begin{array}{c}\text { Spectral } \\
\text { Exponent } \\
\gamma\end{array}$ & $\begin{array}{c}\text { Spectral } \\
\text { Strength } \\
w_{2}\left(\mathrm{~cm}^{4}\right)\end{array}$ & $\begin{array}{c}\text { Sound } \\
\text { Speed } \\
\text { Ratio } \\
v\end{array}$ & $\begin{array}{c}\text { Density } \\
\text { Ratio } \\
\rho\end{array}$ & $\begin{array}{c}\text { Sed Atten } \\
\text { Constant } \\
(\mathrm{dB} / \mathrm{m} / \mathrm{kHz}) \\
k_{p}\end{array}$ & $\begin{array}{c}\text { Volume } \\
\text { Scatter } \\
\text { Coeff } \\
\sigma_{\mathrm{u}}\left(\mathrm{m}^{-1}\right)\end{array}$ \\
\hline Sand & 1.5 & 3.00 & 0.0095 & 1.178 & 1.845 & 0.492 & 0.43 \\
\hline Silt & 6.7 & 3.30 & 0.0033 & 0.986 & 1.148 & 0.101 & 0.05 \\
\hline
\end{tabular}

optimizations were available (e.g., OCV, TVR, transducer radiation patterns, system gains, ground truth) other components were missing (e.g., the mechanical-electrical transfer function and the independently measured transmit signal), and were thus ignored or approximated. That said, the optimization results summarized here are encouraging and warrant further test and development of the echo envelope acoustic characterization approach.

As previously mentioned, the bottom echoes considered here yield poorly defined temporal features, necessitating the use of a group delay alignment technique. While this technique is the most robust, rising edge characteristics of the returns tend to smear upon echo averaging, resulting in poorer shape matches between model and data - most notable in the sand scenario (Fig. 9a). To overcome this drawback, the model-data alignment step used in our matching algorithm was modified. In previous studies $p_{a}$ and $\hat{p}_{a}$ were aligned along threshold minima before calculation of the S/E model-data merit function. Here, $p_{a}$ and $\hat{p}_{a}$ were aligned along signal maxima before calculation of the $\mathrm{S} / \mathrm{E}$ merit function. Based on the results presented here, model-data matching procedures for "rough" oceanographic surveys may, in general, require: (1) Group delay alignment of echo time series to create $p_{a} ;$ (2) Alignment of $p_{a}$ and $\hat{p}_{a}$ along 
signal maxima preceding $\mathrm{S} / \mathrm{E}$ calculation.

Average echo envelopes calculated from data appear to have excessive levels of energy in the tail portion. This may be due to the physical properties of the seafloor or due to procedural/system effects, such as the uncompensated side lobes in the Line-and-Cone transmit radiation pattern and/or inexact knowledge and subsequent estimation of the Line-and-Cone transmit signal. As was shown by the parameter sensitivity study of [1], an increase in the volume backscatter coefficient $\left(\sigma_{v}\right)$ or an increase in the roughness spectral strength $\left(w_{2}\right)$ results in increased energy backscattered in the tail section of the signal. If the highenergy signal tails of the data are a result of system/procedural effects, then the optimization procedure would likely yield excessive values for $\sigma_{v}$ and/or $w_{2}$.

We endeavored to select granular, spatially homogeneous and isotropic seafloor substrates for this study, as these conditions are assumed in the theoretical acoustic backscatter models employed. Certainly other seafloor types were represented in the data, as implied by the bottom photographs of Fig. 10 .

Currently the acoustic backscatter models employed [10] are not valid for extremely rough, typically rocky, bottoms. Here, the Kirchhoff criteria (tangent slope approximation) used in the models becomes invalid as the rms curvature of the sediment-water interface becomes small compared to the acoustic wavelength. Methods of compensating for this limitation would be to: (1) Develop a large-scale roughness theoretical acoustic backscatter model; (2) Implernent an empirical "quasi-theoretical" large-scale acoustic backscatter model such as described in [15].

\section{CONCLUSIONS}

Normal incidence, $23.5 \mathrm{kHz}$ seafloor acoustic backscatter data and bottom video were measured with the Deep Tow instrument package of the Scripps Institution of Oceanography in 100 meter water depth south of San Clemente Island, CA. The collected data were processed using an echo envelope sediment characterization method, to derive geoacoustic parameters such as particle mean grain size and the strength of the power law characterizing the roughness energy density spectrum of the sedimentwater interface.

Two regions, sand and silt, were selected based on available ground truth, perceived along-track sediment homogeneity, data quality and tow fish stability. Distinction between sand and fine grain sediments can be accomplished by creation of feature vectors comprised of mean grain size $\left(\mathrm{M}_{\phi}\right)$ and interface roughness spectral strength $\left(w_{2}\right)$. Estimates for mean grain size and roughness spectral strength $\left(\mathrm{M}_{\phi}, w_{2}\right)$ were $(1.5,0.0095)$ for sand, and $(6.7,0.0033)$ for silt, where $M_{\phi}$ is expressed in PHI units, and $w_{2}$ has units $\mathrm{cm}^{4}$.

These results are consistent with local ground truth measurements and illustrate the potential of this sediment characterization method in survey mode. Plans for further study include implementation of measured transducer beam

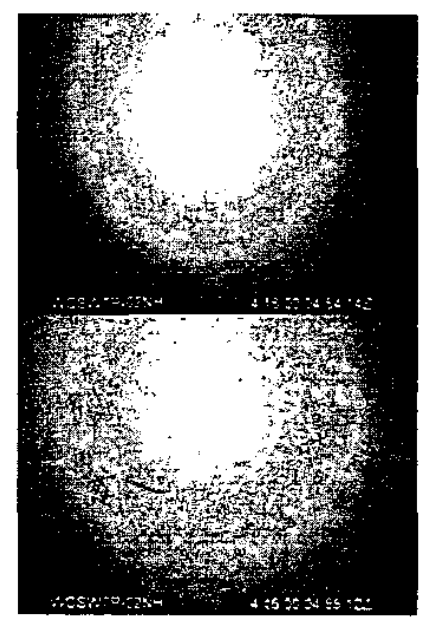

Fig. 10. Photographs: Sand ripples and uniformly rough rock substrates.

patterns in the echo envelop simulation software, and development of a theoretical large-scale roughness acoustic backscatter model for use over rocky terrain.

\section{References}

[1] D. D. Stemlicht, "High Frequency Acoustic Remote Sensing of Seafloor Characteristics," PhD dissertation, University of Califomia, San Diego, 1999.

[2] D. D. Stemlicht and C. de Moustier, "Temporal modeling of high frequency $(30-100 \mathrm{kHz})$ acoustic seafloor backscatter: Shallow water results," Proceedings of High Frequency Acoustics in Shallow Water, NATO SACLANT Undersea Research Center, pp. 509.516, July 1997.

[3] R. J. Urick, Principles of Underwater Sound. McGraw-Hill, Inc., 1983.

[4] C. de Moustier and D. Alexandrou, "Angular dependence of $12 \mathrm{kHz}$ seafloor acoustic backscatter," J. Acoust. Soc. Am. 90(1), 522-531, 1991

[5] M. V. Berry, "On deducing the form of surfaces from their diffracted echoes," J. Phys. A: General Physics, 5:272-29I, 1972.

[6] M. V. Berry. "The statistical properties of echoes diffracted from rough surfaces," Philosophical Transactions of the Royal Society, A273:611-654, 1973.

[7] E. H. Nesbitt, "Estimation of Sea Bottom Parameters using Acoustic Backscattering at Vertical Incidence," Masters thesis, University of Washington, 1988.

[8] E. Pouliquen and X. Lurton, "Identification de la nature du fond de la mer à l'aide de signaux d'écho-soundeurs: 1 . Modélisation d'écho réverbérés par le fond," Acta Acustica, 2(2):113-126, 1994.

[9] X. Lurton and E. Pouliquen, "Identification de la nature du fond de la mer à l'aide de signaux d'écho-soundeurs: Méthode d'identification et résultats experimentaux," Acta Acustica, 2(3): 187-194, 1994.

[10] D. R. Jackson, D. P. Winebrenner, and A. Ishimaru, "Application of the composite roughness model to high-frequency bottom backscattering," J. Acoust.Soc. Am. 79(5), 1410-1422, 1986.

[11] D. L. Baird and C. M. McKinney, "Investigation of the Line-andCone Underwater Sound Transducer," J. Acoust. Soc. Am. 34(10), 1576-1581, 1962.

[12] F. N. Spiess and R. C. Tyce, "Marine Physical Laboratory Deep Tow Instrument System," SIO Reference 73-4, 1973.

[13] C. S. Clay and H. Medwin, Acoustical Oceanography: Principles and Applications, John Wiley \& Sons, 1977.

[14] D. D. Stemlicht and C. P. de Moustier, "Stacking and averaging techniques for bottom echo characterization," Proceedings: $16^{\text {ih }}$ International Congress on Acoustics and $135^{\text {th }}$ Meeting Acoustical Society of America, vol. IV, pp. 3023-3024, 1998.

[15] Applied Physics Laboratory, "High-Frequency Ocean Environmental Acoustic Models Handbook," Technical report, University of Washington, 1994. 